\title{
Public Comment on Draft NOAA Citizen Science Strategy
}

\author{
LEA A. SHANLEY, University of Wisconsin \\ PIETRO MICHELUCCI, Human Computation Institute \\ KRYSTAL TSOSIE, Vanderbilt University \\ GEORGE WYETH, Environmental Law Institute \\ JULIA KUMARI DRAPKIN, ISeeChange, Inc. \\ KRYSTAL AZELTON, Secure World Foundation \\ DARLENE CAVALIER, SciStarter \\ JASON HOLMBERG, Wild Me
}

\section{ABSTRACT}

This guest editorial briefly describes a history of activities related to encouraging the U.S. federal government to use and support citizen science, and presents the recent public comments that we submitted to the U.S. National Oceanic and Atmospheric Administration (NOAA) in response to its 2020 Federal Register Call for Public Comment on its draft citizen science strategy, which was officially published in January 2021.

\section{EDITORIAL}

The U.S. National Oceanic and Atmospheric Administration (NOAA) published a draft citizen science strategy in the fall of 2020 and invited public comments through the Federal Register. Below we include a verbatim copy of our response to this invitation, submitted on September 8 , 2020. It is preceded by an editorial account of efforts to build broad U.S. federal government support for citizen science.

Numerous federal agencies have embraced citizen science and crowdsourcing as an approach to public engagement and education. They also are beginning to see these methodologies as an 
opportunity to help solve scientific and engineering challenges, to monitor environmental conditions, to advance their missions and improve service delivery, and to promote a spirit of curiosity and volunteerism. Federal support, however, has not always been a given. While some agencies like the National Science Foundation (NSF) and the National Institutes of Health (NIH) have long-supported citizen science (e.g., [1]), other agencies have been somewhat cautious about using "non-traditional" or "non-authoritative" data, particularly given Congressional oversight and the potential for litigation [2].

Launched by The Wilson Center in Washington, D.C., in 2011, and sponsored by Alfred P. Sloan Foundation, the Commons Lab initiative helped to pave the way for broader government adoption of citizen science. Over the course of four years, the Lab commissioned nineteen studies identifying and prioritizing research challenges, risk reduction strategies, data quality assurance, and best practices for crowdsourcing and citizen science. Serving as a bridge organization, the Lab also organized monthly roundtables that connected government employees with academic researchers, nonprofits, industry, and grassroots groups engaged in crowdsourcing and citizen science. The Lab initially focused on the application of these approaches for geosciences, disaster management, and humanitarian relief, but the scope expanded over time as the challenges, like data quality and volunteer motivation, were common across disciplines. One such workshop, sponsored by the Computing Community Consortium and co-hosted by the Commons Lab at The Wilson Center, developed a research roadmap for Human Computation, providing a vision for human-machine teaming through citizen science and crowdsourcing [3]. It also highlighted some of the risks, such as the potential spread of dis-/misinformation [4], particularly as government agencies begin to rely on citizen science and crowdsourcing information and data for decisionmaking.

In 2013, in order to increase the findability of federal citizen science projects, to assess the gaps and opportunities in application areas, and to understand the extent of federal investments in citizen science, the Commons Lab initiated the development of a Catalog of federal citizen science projects, in close collaboration with the emergent FedCCS, the Citizen Science Association, Citsci.org, and SciStarter.org. SciStarter, in particular, provided the database design and initial projects dataset. These activities culminated in a November 2013 workshop titled New Visions for Citizen Science [5]. Workshop participants coalesced around the idea for a Federal Crowdsourcing and Citizen Science Toolkit, which would provide federal employees with a stepby-step "how to" for designing, launching, and managing citizen science projects in the federal context. The workshop also resulted in the formal establishment of the Federal Community of Practice for Crowdsourcing and Citizen Science (FedCCS) in January 2014.

The Commons Lab and FedCCS members worked together to expand high-level support for citizen science, and in particular, for the Federal Citizen Science Catalog and Citizen Science Toolkit. This included significant outreach with agency Administrators, Chief Scientists, and executives, with the White House Office of Science and Technology Policy (OSTP), with many 
of the subcommittees of the National Science and Technology Committee (NSTC), including the US Group on Earth Observations (GEO) and the Subcommittee for Disaster Reduction (SDR), and with The Networking and Information Technology Research and Development program (NITRD). Ultimately, we wanted to embed citizen science in federal policies across the government. A collaboration between the Commons Lab and the U.S. Global Climate Change Research Program (USGCRP), for example, resulted in citizen science being highlighted in the National Climate Assessment [6]. The Commons Lab and FedCCS also informed the first National Civil Earth Observation Plan [7]. Briefings organized by the Commons Lab with the Office of Senator Coons in early to mid-2014 and by SciStarter.org with congressional staff in 2015 catalyzed and helped to propel the Crowdsourcing and Citizen Science Act [8]. The prompt for this legislation was the need expressed by federal lawyers and staff to clarify authorization for federal agency use of citizen science, and to address barriers to federal support, such as the AntiDeficiency Act and liability concerns.

Building on the Obama White House Champions of Change Citizen Science event [9], OSTP incorporated the ideas for the Catalog and Toolkit into the Second U.S. Open Government National Action Plan [10] (see also [11]). The Plan, released October 31, 2013, stated that the United States would commit to "harness the ingenuity of the public by enabling, accelerating, and scaling the use of open innovation methods such as incentive prizes, crowdsourcing, and citizen science within the Federal Government." These goals were achieved through the mobilization of 125 hardworking federal staff in 2015. The Commons Lab studies articulated the need for and the FedCCS provided significant input on the White House Memorandum on Crowdsourcing and Citizen Science [12], which went through multiple rounds of agency review to get consensus. This memorandum was intended to provide top-level encouragement and guidance for the appropriate use of citizen science within the federal government. It called for agencies to contribute projects to the Catalog and to designate an agency liaison who would both serve as an internal resource and help with interagency coordination for citizen science. We also incorporated some of the key ideas from the European Citizen Science Association's Ten (Ethical) Principles of Citizen Science.

The Toolkit, Memorandum, and proposed legislation were rolled out at the first White House Citizen Science Summit in 2015, which was spear-headed and co-organized by the FedCCS. The event, titled Open Science and Innovation: Of the People, By the People, For the People, intentionally aligned citizen science with the emergent Open Science movement. The President's Science Advisor Dr. John Holdren, the Director of the National Science Foundation Dr. France A. Cordova, and the CEO of the American Association for the Advancement of Science Dr. Rush D. Holt -- the heads of the nation's leading science organizations -- endorsed citizen science in speeches during this event. FedCCS, SciStarter, and the Citizen Science Association also joined forces to announce the first Citizen Science Day, which has now grown into an annual Global Citizen Science Month. As a culmination of the FedCCS community's efforts, the FedCCS, Toolkit, and Catalog were bundled as the three core components of Citizenscience.gov in 2016. 
That year, the citizen science legislation also was passed into law, and the Government Accountability Office (GAO) provided an assessment of federal open innovation and citizen science efforts [13].

Over time, the FedCCS blossomed from eight original members representing the Commons Lab, NIH, EPA, and NOAA to more than 350 federal staff representing 60 federal departments and agencies. Concurrently, agencies, such as the U.S. Environmental Protection Agency, the U.S. Geological Survey (USGS), the National Oceanic and Atmospheric Administration (NOAA), NASA, U.S. Forest Service (USFS), NSF, and NIH, among others, grew thriving internal citizen science communities of practice. The 2018 National Academies of Science, Engineering and Math consensus study titled, Learning Through Citizen Science: Enhancing Opportunities by Design, offered federal agencies a research agenda to advance our understanding of how citizen science can support science learning and enhance science education. It also underscored the growing credibility of this emergent field [14].

Federal support for citizen science and crowdsourcing continued through the Trump Administration, resulting in the adoption of agency-specific citizen science strategies and policies, as well as reporting to Congress to comply with the requirements of the Crowdsourcing and Citizen Science Act (e.g., [15]). In 2020, NOAA issued a Federal Register request for public comment on their draft Citizen Science Strategy. Below we have included our submission (Sept $8,2020)$ to NOAA's request for public comments [16], offering a few key areas where the Federal government could help to advance the science of citizen science, integrate new technologies like machine learning and distributed sensor networks, and importantly, broaden participation. We are delighted to see that some of our recommendations were incorporated into the final agency strategy [17], as well as to hear from our NOAA colleagues that our public comments were helpful in their thinking towards the development of NOAA's citizen science implementation plan. While there is still much to do, we have been impressed by their leadership and commitment to engaging the public in real world science. As we go forward with a "whole of government" and "whole of community" approach, we hope that the citizen science community expands their efforts to engage and inform policy makers and government organizations at all levels, from the local to the international [18]. The potential for impact is great!

\section{Public Comment on Draft NOAA Citizen Science Strategy}

September 8, 2020

Dear NOAA Citizen Science Program Officers: 
Thank you for the opportunity to submit comments on the NOAA Draft Citizen Science Strategy. We applaud NOAA for taking the leadership role in developing several important agency wide strategies, including NOAA's Draft Citizen Science Strategy, which fosters and supports a culture of innovation, and which engages a range of stakeholders and the public in NOAA's scientific enterprise.

We especially encourage NOAA to:

- explore the role of citizen science in augmenting and enhancing NOAA's strategic activities in machine learning, integrated sensing and analysis, cloud computing, and Earth observations;

- develop collaborative partnerships with tribal education programs and emerging STEM workshops geared towards K-12 students and tribal colleges and universities, co-creating citizen science programs so that they are culturally-consistent with Indigenous worldviews in science;

- develop strategic partnerships with the private sector, non-profits, academic institutions, and local, state, and tribal governments to advance the effective and efficient use of citizen science and related participatory approaches to meet NOAA's mission, to address scientific and societal goals, and to unleash the power of local communities.

Please see our comments below and attached. Thank you for your consideration.

Sincerely,

Lea A. Shanley, Ph.D., Nelson Institute, University of Wisconsin, Madison, WI

Co-Chair, Citizen Science Law \& Policy Working Group, Citizen Science Association

Co-Chair, Group on Earth Observations Citizen Science Community Activity

Co-founder and former co-chair, Federal Community of Practice on Crowdsourcing and Citizen

Science

Pietro Michelucci, Ph.D.

Director, Human Computation Institute

Visiting Scientist, Cornell University, Ithaca, New York

Editor-in-chief, Human Computation

Founder, Stall Catchers citizen science project

Krystal Tsosie, MPH, MA

Doctoral Candidate, Vanderbilt University, Nashville, TN

Research Faculty, Turtle Mountain Community College, Belcourt, ND

Co-Founder, Native BioData Consortium, Eagle Butte, SD

George Wyeth, JD 
Co-Chair, Citizen Science Law \& Policy Working Group, Citizen Science Association Visiting Scholar, Environmental Law Institute, Washington, DC (This affiliation is provided for identification only; the comments do not reflect the views of the Environmental Law Institute.)

Julia Kumari Drapkin

Founder and CEO, ISeeChange, Inc., New Orleans, Louisiana

Echoing Green Fellow, 2019-2021

MIT Solve, 2018-2019

Krystal Azelton

Director of Space Applications Programs, Secure World Foundation, Washington, DC

Darlene Cavalier

Professor of Practice, School for the Future of Innovation in Society, Arizona State University, Tempe, AZ

Founder and CEO, SciStarter.org

Jason Holmberg

Founder and Executive Director, Wild Me, Portland, Oregon

\section{The Power of Citizen Science and Crowdsourcing}

Through citizen science, millions of volunteers across our Nation actively contribute valuable time and expertise to help advance our understanding of the world around us. Citizen science encompasses a range of methodologies that support meaningful contributions of the public to the advancement of scientific and engineering research and monitoring, in ways that may include, for example, collaboratively:

- identifying research questions;

- collaboratively designing and conducting scientific investigations;

- designing, building and/or testing low cost sensors;

- developing scientific hardware and software;

- collecting, processing, and analyzing data;

- developing data applications and visualizations; and,

- collaboratively solving complex problems.

We would like to emphasize that citizen science goes well beyond data collection, and citizen scientists may be included in and contribute to all aspects of the scientific process. We must move beyond siloing citizen scientists in data collection, and consider how projects may integrate various forms of participatory approaches into their activities. 
Similarly, crowdsourcing is a methodology that engages a large group of people through an open call to tackle a common task or problem, either as individuals or collectively. This may include asking the public to submit new ideas, designs, algorithms, or data via an online platform or mobile app, which is sometimes incentivized through a prize or challenge.

\section{What are the benefits of Citizen Science?}

Citizen science and crowdsourcing, when designed well and used appropriately, may augment and enhance traditional scientific approaches and observing systems, allowing us to do more science, more effectively. The benefits of these approaches are many; they may allow scientific endeavors to:

- $\quad$ solve challenging scientific problems;

- improve spatial or temporal resolutions;

- increase geographic extent or temporal scale;

- analyze imagery and Big Data more rapidly and where computer algorithms don't suffice (e.g., developing training data sets for supervised machine learning);

- generate new data applications and technologies;

- $\quad$ provide hands-on STEM learning, and increase scientific literacy and awareness of topical issues and scientific research methods; and,

- $\quad$ improve delivery of government services with significantly lower resource investments.

- connect citizens to the missions of Federal agencies by promoting a spirit of open government and volunteerism.

\section{Opportunities for Citizen Science to Support Other NOAA Strategies}

These participatory approaches help to advance American innovation, and are integral components to achieving the federal government's and NOAA's priorities in Artificial Intelligence, Open Science, Open Government, and Open Data.

- Artificial Intelligence (AI) and Citizen Science: Being able to accurately and comprehensively predict the behaviors and interactions of interdependent earth systems, such as the biosphere, society, and human behavior, enables the formulation of sustainable solutions that satisfy multiple stakeholders. The information processing capabilities needed to achieve such complex modeling exist today largely in isolation. Hybrid information processing systems that leverage the complementary strengths of human cognition and artificial intelligence are already solving problems that cannot be addressed by humans or machines alone. Most machine-based predictive modeling learns by example from huge training data sets that require tremendous human effort to create. Citizen science enables the rapid generation of human-generated data that can teach these data-hungry computers to perform tasks almost at the human level. In other words, Citizen science is a high-demand resource for human-assisted machine learning. The 
resultant AI systems perform at levels approaching human capability, but sometimes see the problems in different ways. These complementary thinking styles are now being combined to produce synergies not only in terms of improving predictions but also in the ongoing learning of both machines and humans from each other.

Integrated Sensing and Analysis: The proliferation of physical sensors connected to the Internet (i.e., the Internet of Things, or "IoT") has created a tremendous opportunity to improve our understanding of causal relationships in the real world, and to anticipate and respond to changing conditions in real time. Such streaming data could be used both to improve our prediction models and to create automated and adaptive response systems. However, using these new kinds of sensor data for these purposes requires interpretability and integration, which is lacking today. Citizen Science provides an immediate mechanism for transforming sensor data into actionable information, which also then can be used to train automated systems to do the majority of the work. Moreover, if we had both humans and machines within the same information processing ecosystem (e.g., Civium.io), we could fluidly implement an initial phase of human-based analysis, followed by gradual instruction and hand-off to machines, while keeping some humans in the loop to handle any new data patterns that are uninterpretable by the machines. In this configuration, citizen science becomes a key component to building the next generation of AI, which constantly improves itself by learning from human examples and can delegate difficult questions back to humans for help when needed.

Recommendation: We encourage NOAA to consider the role of citizen science in supporting and enhancing NOAA's AI Strategy, NOAA's Unmanned Systems Strategy, and related activities.

Recommendation: New research platforms that integrate citizen science and cloud-based computing are needed to support the rapid advancement of methods that leverage citizen science and AI synergistically.

Recommendation: We encourage NOAA to apply its unique lens on interconnected systems to consider Citizen Science as an on-ramp for developing adaptive systems that leverage both humans and machines for processing live sensor data in real time, toward knowing sooner and responding better to evolving conditions.

Recommendation: As NOAA works to develop trustworthy AI systems, it's critical to develop and train these systems with data that is unbiased and to develop algorithms that can be easily explained. Sometimes the data used to train machines may correctly convey real-world bias, but this bias can be misinterpreted when key context is missing [20]. It's therefore paramount to provide sufficient context to human decision-makers who rely on these models' predictions so they can understand where and how to use them in bias-safe ways. 
- Cloud Computing and Citizen Science: Methods that enable and foster such synergies rely critically on cloud-based infrastructure for both data persistence and high performance computing. Unless policies supporting the advancement of citizen science and other forms of human-in-the-loop computing do not plan for the sustenance of such systems, we will continue to see such projects lose steam after the innovation phase, just as they begin to make research impacts. On the human computation side, the proliferation of citizen science success cases helps inform repeatable methods for public engagement. The societal response to the current pandemic has accelerated an ongoing transition from the knowledge economy to a thinking economy, in which online cognitive labor (or "click-working") has become a growing sector. However, the conception of increasingly sophisticated AI and hybrid predictive modeling methods enabled by faster processing speeds, ironically calls for increased computing resources to support practicable versions of these systems. Not only do we need to provide enduring cloud computing support for these systems, but we also need to improve computing efficiency and identify low-impact energy sources to power them.

Recommendation: We encourage NOAA to consider how the NOAA Cloud Strategy may enhance the NOAA Citizen Science Strategy. We encourage NOAA to work with the NOAA OCIO, the Office of Management and Budget, the General Services Administration, private industry experts, and the citizen science research community to develop methods for optimizing the usage of cloud services for citizen science.

Recommendation: Similar to the National Science Foundation's CloudBank program for NSF principal investigators (e.g., https://www.nsf.gov/pubs/2020/nsf20108/nsf20108.jsp; and https://www.nsf.gov/pubs/2019/nsf19510/nsf19510.htm), we encourage NOAA to consider providing free cloud computing and storage resources to NOAA researchers (based on a lightweight low-bar proposal) on an annually renewable basis, particularly when researchers demonstrate ongoing (mission-aligned) research impacts that cannot be otherwise achieved without access to cloud compute and storage services. Successful adoption of cloud technologies also will require training and technical support to help researchers adapt and implement cloud services for their individual resource projects. This solves two problems simultaneously: (1) it reduces the barrier to entry to cloud computing for citizen science research projects, thus stimulating the creation of new projects; and, (2) it provides enduring support for sustaining projects and data sets that are delivering scientific and/or societal impact, which is an ongoing incentive for project stakeholders to make good on those objectives. This also would make NOAA's investments in citizen science data more broadly accessible, supporting open science and reproducibility of science, as well as more usable in aggregate to advance NOAA priority areas, such as hurricane, flooding, and weather research.

- Open Science and Citizen Science: The OECD's 2015 "Making Science a Reality" white paper includes citizen science as a form of open science. Open science can improve 
broader access to scientific data, results, and journal articles; it can increase transparency and foster reproducibility of scientific research. Citizen science similarly contributes to these goals through the participatory contributions of citizen scientists to research, collection, analysis, and publication of open data, as well as to the co-creation of open source scientific hardware and software. Both Open Science and citizen science may facilitate knowledge transfer between the scientific community, policymakers, and the general public, increasing scientific literacy and awareness of scientific results (e.g., [21] Voehland and Gobel 2017; Citizen Science and Open Science Community of Practice: http://citizenscienceglobal.org/projects.html\#csos).

Recommendation: We encourage NOAA to include discussion of citizen science and related approaches in NOAA executive level engagement and communications with key stakeholders, including NOAA Oceanic and Atmospheric Research (OAR) and the NSTC Subcommittee on Open Science.

- Earth Observation and Citizen Science: Citizen science and crowdsourcing are beginning to play an important role in augmenting and enhancing Earth observation data for a wide range of applications - air quality monitoring, disease monitoring, food security, disaster response, sustainable development, and land cover or land-use change, among other topics. For instance, volunteers may interpret and classify satellite imagery, often training algorithms for machine learning. They also can take in-situ measurements for calibration and validation activities or to fill gaps in Earth observation data. As institutions attempt to innovatively incorporate citizen science into their traditional Earth observation workflows, however, they also will face many challenges - from data quality and data fusion to formulating policies that will facilitate this work.

Nonetheless, human-based distributed sensing, which also can be low-tech, is an evolving research area in its own right, including approaches such as collective sensing, which involves applying statistical methods to aggregated social network data; people as sensors, which involves humans in the field contributing their subjective perceptual experiences via mobile devices; and participatory sensing, in which humans use portable sensor technology to acquire objective data from the world" [22].

Recommendation: We encourage NOAA to incorporate citizen science and related participatory approaches into NOAA NESDIS priorities and activities.

Recommendation: We also encourage NOAA to consider how citizen science and related participatory approaches may augment and enhance NOAA's in situ observation networks, including NOAA's Integrated Ocean Observing System (IOOS).

Recommendation: We ask that NOAA work with the U.S. Group on Earth Observations to encourage and support the incorporation of citizen science and related participatory approaches into the National Civil Earth Observations Strategy and Implementation Plans, and US GEO activities. 
Recommendation: We also encourage NOAA to work with the intergovernmental Group on Earth Observations (GEO) to support the integration of citizen science and related participatory approaches into common US and GEO priority areas, as appropriate.

- Open Data: We would encourage NOAA to make more of its data accessible to citizen science projects, small businesses, and the public, especially in formats that they can easily use without having to make investments in high-cost software. To this end, providing tutorials also would be very beneficial.

At the same time, it is not always appropriate to make citizen science data open and publicly available (e.g., personally identifiable information, as per the Privacy Act, and health information, as per HIPPA). Special attention also should be paid to the appropriate handling of location information, which could potentially reveal the (real time) location of citizen scientists themselves or of endangered species, putting them at risk.

\section{Ethical Principles in Citizen Science}

Recommendation: As was done with the White House Memorandum on Crowdsourcing and Citizen Science, we urge NOAA to consider incorporating many of the "10 Principles of Citizen Science", developed by the European Citizen Science Association, into its Citizen Science strategy and implementation plan.

The "10 Principles of Citizen Science" include:

1. "Citizen science projects actively involve citizens in scientific endeavors that generate new knowledge or understanding.

2. Citizen science projects have a genuine science outcome.

3. Both the professional scientists and the citizen scientists benefit from taking part.

4. Citizen scientists, if they wish, may participate in multiple stages of the scientific process.

5. Citizen scientists receive feedback from the project.

6. Citizen science is considered a research approach like any other, with limitations and biases that should be considered and controlled for.

7. Citizen science project data and meta-data are made publicly available (e.g., via NOAA's Cloud), and where possible, results are published in an open access format.

8. Citizen scientists are acknowledged in project results and publications for their contributions. For example, citizen scientists may be included as co-authors when their contributions are significant. 
9. Citizen science programs are evaluated for their scientific merit, output, data quality, participant experience, and wider societal or policy impact.

10. The leaders of citizen science projects take into consideration the legal and ethical issues surrounding data ownership, copyright, data sharing agreements, confidentiality, attribution," and privacy.

\section{Citizen Science and Indigenous Data Sovereignty}

American Indian Tribes have long been concerned about ownership, control, and access to data about their lands, resources, communities, and families. The development of sophisticated technologies for data collection and analysis, such as high-resolution remote sensing, GIS and machine learning, have heightened these concerns. Tribe's concerns about the potential misuse of data include, but are not limited to: infringement on individual and group privacy; misappropriation of intellectual property and its use for commercial gain; misinterpretation or discrediting of cultural practices; abrogation of treaty rights; and the impact on the Federal-Tribal Trust relationship. Protecting tribal data from potential misuse, while at the same time ensuring access for tribes and their members, will require a creative combination of technical, legal, policy, and organizational research and solutions. Several initiatives have begun to tackle these issues head on, including the development of the CARE Principles for Indigenous Data Governance, the launch of IEEE P2890: Recommended Practice for Provenance of Indigenous Peoples Data, and the international growth of the Indigenous Data Sovereignty networks, including the Global Indigenous Data Alliance. Tribal governments also will strengthen their sovereignty by building capacity to understand and use these emerging technologies to their own advantage. Data science is the new frontier in Self-Determination.

Recommendation: We strongly encourage NOAA citizen science efforts to adopt the CARE data governance principles when working with tribal governments and communities.

Recommendation: There are many potential opportunities for NOAA to consider partnerships with tribal education programs and emerging STEM workshops geared towards K-12 students and tribal colleges and universities. We encourage NOAA citizen science efforts to also consider tailoring programs that are culturally-consistent with Indigenous worldviews in science. We also hope NOAA will consider partnering with existing tribal-based education programs and organizations to provide hands-on STEM learning opportunities for all training levels.

Recommendation: Know that tribal sovereignty within the US is not recognized for all Indigenous groups. There are state-recognized and unrecognized tribes that may not have formal Federal-Tribal Trust relationships. Also, Alaska Natives and Native Hawaiians have a different or "special" relationship with the US. Additionally, while many tribally enrolled citizens reside outside of tribal jurisdiction (due to differences in economic opportunities and forcible land removal), cultural boundaries and tribal identities should still be respected. 
Recommendation: Indigenous people have resided within their tribal homelands for many centuries. Therefore, their Indigenous Knowledge (IK) and Tribal Ecological Knowledge (TEK) systems could be very enlightening and enriching for citizen science. There are ways to mutually share the knowledge without appropriation, and citizen science principles should always come from a perspective of respect.

\section{Diversity, Equity, and Inclusion in Citizen Science}

We applaud the emphasis on ensuring diversity, equity, and inclusion in citizen science project design and implementation to maximize the benefits of citizen science (Goal \#2,b). Communities of color have been largely absent in citizen science projects to date. We need to provide concrete benefits to these communities, develop collaborative partnerships rather than top down arrangements, sustain genuine contact, and identify and address the barriers to participation (e.g., Philips 2020; [19] Porticella et al, 2012).

Recommendation: True collaboration requires consultation with these communities before the work is defined and launched, and may mean reframing the goals or focus of the work to address community priorities as well.

Recommendation: In order to achieve this goal, we recommend that NOAA develop D\&I performance evaluation metrics and guidance materials and training opportunities for agency sponsored and/or led citizen science projects to ensure diversity, equity and inclusion is successfully achieved.

Recommendation: We encourage NOAA to develop performance metrics to understand the current status and track progress on diversity, equity, and inclusion for agency led or funded citizen science projects.

Recommendation: We encourage NOAA to establish guidelines and mechanisms for individuals and communities to file complaints and/or seek mediation should any issues arise that may include discrimination, harassment, project mismanagement, and/or other potential negative impacts to the community. Penalties could include censure of project principal investigator(s) and/or cessation of agency funding for the project.

\section{Value of Citizen Science and Related Efforts}

Citizen science and crowdsourcing projects can enhance scientific research and address societal needs, while drawing on previously underutilized resources. For example, after analyzing 338 citizen science biodiversity projects around the world, researchers at the University of Washington estimated that the in-kind contributions of 1.3-2.3 million citizen science volunteers to biodiversity research have an economic value of up to $\$ 2.5$ billion per year. 
Recommendation: We encourage you to engage NOAA's Chief Economist and organizations such as Resources for the Future's VALUABLES initiative to assess the return on investment, as well as the economic value of citizen science and crowdsourcing collected information, to the NOAA scientific enterprise.

\section{Grants, Procurement, and Public-Private Partnerships}

We appreciate that NOAA has targeted grant programs supporting external citizen science projects.

Recommendation: In addition to targeted citizen science solicitations, we also would recommend that NOAA encourage citizen science proposal submissions for the full range of research grant programs available through NOAA.

Private sector companies and non-profit organizations, such as Microsoft Research, SciStarter, iSeeChange, ESRI, Radiant Earth Foundation, and Maxar/DigitalGlobe, have provided expertise, online platforms, cloud compute and storage, and/or other tools and resources to support citizen science and crowdsourcing projects. Private companies like Verizon and others are collaborating with SciStarter to encourage their employees to participate in citizen science projects as part of their corporate social responsibility activities [23].

Libraries are strong community anchors, enhance civic engagement, and help prepare people to be full participants in their local and global societies. Arizona State University and SciStarter developed well-designed collaborations between libraries and citizen science partners, which have proven to address critical barriers in citizen science infrastructure--including low awareness of citizen science and lack of access to instruments and resources--which prohibits broad, quality participation in citizen science.

Recommendation: We encourage NOAA to identify and develop strategic partnerships with the private sector, non-profits, academic institutions, libraries, and local, state, and tribal governments to advance the effective and efficient use of citizen science and related participatory approaches to meet NOAA's mission, to address scientific and societal goals, and to unleash the power of local communities. This includes allowing small businesses and other non-academic research organizations to serve as principal investigators for citizen science projects, as well as streamlining the procurement process to make it easier for small businesses and non-academic research organizations to submit proposals. To this end, we encourage NOAA to develop guidelines, templates, and tutorials for procurement of necessary services, tools, and resources to support citizen science and crowdsourcing projects at NOAA.

In conclusion, we applaud NOAA for taking the leadership role in developing several important agency wide strategies, including NOAA's Draft Citizen Science Strategy, that help to foster and support a culture of innovation within the agency. We respectfully suggest the following edits, in addition to the comments above: 


\begin{tabular}{|c|c|c|}
\hline Page & Para. & Suggestion \\
\hline 3 & 3 & $\begin{array}{l}\text { Terms for similar or related activities include, but are not limited to: volunteer monitoring, } \\
\text { community science, community remote sensing, participatory mapping, volunteered } \\
\text { geographic information (VGI), crisis mapping, and public participation in scientific } \\
\text { research (PPSR). }\end{array}$ \\
\hline 3 & 4 & $\begin{array}{l}\text { It also may be useful to include "ideation" among the approaches included within this } \\
\text { policy. }\end{array}$ \\
\hline 4 & 2 & $\begin{array}{l}\text { To leverage the ingenuity of the American public and optimize the use of innovation to } \\
\text { help meet its mission, NOAA seeks to apply best practices, evaluate performance, assess } \\
\text { impacts, and have access to the latest tools and techniques. }\end{array}$ \\
\hline 4 & 3 & $\begin{array}{l}\text { Objectives: } \\
\text { b. Increase intra-agency coordination and collaboration, awareness, and capacity of the } \\
\text { agency to use citizen science and related participatory approaches as a viable and } \\
\text { increasingly capable tool to engage the American public in helping NOAA meet its } \\
\text { mission. }\end{array}$ \\
\hline 4 & 3 & $\begin{array}{l}\text { c. Develop flexible and diverse performance evaluation plans and metrics to track project } \\
\text { outcomes and impacts. }\end{array}$ \\
\hline 4 & 3 & $\begin{array}{l}\text { f. Support interagency coordination and collaboration through participation in the Federal } \\
\text { Community of Practice on Crowdsourcing and Citizen Science (FedCCS). }\end{array}$ \\
\hline 4 & 4 & $\begin{array}{l}\text { b. Ensure diversity, equity, and inclusion are considered in project design, implementation, } \\
\text { and performance evaluation to maximize public engagement and the benefits of citizen } \\
\text { science. } \\
* * \text { Note: In order to achieve this goal, we recommend that NOAA develop D\&I guidance } \\
\text { materials and training opportunities for agency sponsored and/or led citizen science } \\
\text { projects to ensure effective diversity, equity and inclusion. }\end{array}$ \\
\hline 5 & 3 & $\begin{array}{l}\text { b. Provide strategies, guidelines, and templates to aid NOAA projects in applying and } \\
\text { documenting best practices for evaluating and assuring data quality. }\end{array}$ \\
\hline 5 & 3 & $\begin{array}{l}\text { C. Encourage NOAA projects to maximize accessibility of their data and meta-data, and to } \\
\text { provide transparency in the presentation of the methods by which data are collected and } \\
\text { analyzed. }\end{array}$ \\
\hline 5 & 3 & $\begin{array}{l}\text { e. Ensure NOAA sponsored or applied citizen science data adhere to the principles and } \\
\text { support the goals of NOAA's Data Strategy, as well as the FAIR Data principles for } \\
\text { scientific data management and stewardship. See } \\
\text { https://www.nature.com/articles/sdata201618 } \\
\text { ** When working with tribal nations, also please consider adhering to the CARE Principles } \\
\text { for Indigenous Data Governance. See https://www.gida-global.org/care }\end{array}$ \\
\hline
\end{tabular}




\begin{tabular}{|c|l|l|}
\hline 6 & $\begin{array}{l}\text { With respect to objective "d", citizen science, crowdsourcing, and related approaches may } \\
\text { contribute to a wide range of domain areas across the Earth sciences (e.g., oceanography, } \\
\text { hydrology, atmospheric sciences), environmental sciences, biological sciences (e.g., fish, } \\
\text { coral reefs, marine mammals), coastal management, hazards (e.g., algal blooms, tsunami, } \\
\text { hurricanes), engineering, social and behavioral sciences, and much more. } \\
\text { We encourage NOAA to look to a broader range of applications and hence to a broader } \\
\text { range of partners and stakeholders than previously considered. }\end{array}$ \\
\hline $\mathbf{6}$ & $\begin{array}{l}\text { With respect to objective "e", we encourage NOAA to include discussion of citizen science } \\
\text { and related approaches in NOAA executive level engagement and communications with } \\
\text { key stakeholders, including: the NSTC Select Committee on STEM Education; the } \\
\text { International S\&T* Coordination Subcommittee (to encourage and coordinate global scale } \\
\text { citizen science efforts); the Interagency Arctic Research Policy Committee; U.S. Group on } \\
\text { Earth Observations (USGEO) Subcommittee; Subcommittee on Global Change Research; } \\
\text { Earth System Predictability Fast Track Action Committee; Subcommittee on Ocean } \\
\text { Science S\&T and relevant interagency working groups (HABS, Ocean Acidification, } \\
\text { Ocean Observations, Ocean and Coastal Mapping); Space Weather, Operations, Research, } \\
\text { and Mitigation IWG; Subcommittee on Open Science; Physical Sciences Subcommittee; } \\
\text { and Biological Sciences Subcommittee, and the Federal CIO Council. }\end{array}$ \\
\hline $\mathbf{6}$ & $\begin{array}{l}\text { U.S. Forest Service, Citizen Science Association, and other organizations with experience } \\
\text { in conducting similar training may provide options to develop skills, understandings, and } \\
\text { expertise. } \\
\text { Also please consider offering specific training in D\&I for citizen science project } \\
\text { coordinators and principal investigators, etc. }\end{array}$ \\
\hline 1 & $\begin{array}{l}\text { We encourage NOAA to consider how citizen science may contribute to and/or benefit } \\
\text { from NOAA's other science and technology strategies, including Artificial Intelligence, } \\
\text { Cloud computing, Data, and Unmanned systems. A whole-of-agency and whole-of- } \\
\text { community -- or rather a systems approach -- is necessary to navigate today's complex } \\
\text { challenges that face the nation and the world. }\end{array}$ \\
\hline 2 & \\
\hline 1 &
\end{tabular}

\section{REFERENCES}

[1] Center for the Advancement of Informal Science Education (CAISE). 2021. STEM Learning in Citizen Science Projects and Programs Repository. Accessed March 15, 2021. Available at: https://www.informalscience.org/projects/learn-experience/citizen-science

[2] Gedney, M., and Shanley, L. A. 2014. Barriers and Accelerators to Crowdsourcing and Citizen Science in Federal Agencies: An Exploratory Study. Commons Lab Blog. September 5, 2014. Washington, D.C.: The Commons Lab of The Wilson Center. Accessed March 15, 2021. Available at: https://stipcommunia.wordpress.com/2014/09/07/anexploratory-study-on-barriers/

[3] Michelucci, P., Shanley, L.A., Dickinson, J., Hirsch, H. A, Bloomberg, M., and Witbrock, M. 2014. U.S. Human Computation Roadmap. Washington, D.C.: Computing Community Consortium (CCC). https://cra.org/ccc/wpcontent/uploads/sites/2/2015/05/Final-HC-Report.pdf 
[4] McDonald, D., Ackley, D., Brynt, R., Gedney, M., Hirsch, H., Shanley, L. 2014. Antisocial Computing. ACM Interactions Forums. XXI 6, November-December 2014. Accessed March 15, 2021. Available at: https://interactions.acm.org/archive/view/november-december-2014/antisocial-computing

[5] Commons Lab. 2013. New Visions for Citizen Science Workshop hosted at the Wilson Center in Washington, D.C., on November 30, 2013. Accessed on March 15, 2021. Available at: https://www.wilsoncenter.org/event/newvisions-for-citizen-science

[6] Kenney, M.A., Cloyd, E., Shanley, L., Tyson, E., Arnold, M., Maguire, A., Lamoureux, A., McLaughlin, J., French, R., Weltzin, J., Wiggins, A., Shirk, J., Wee, B. 2014. Tracking a Changing Climate. Citizen Science Contributions to the National Climate Assessment: Workshop Report. Accessed March 15, 2021. Available at:

https://www.globalchange.gov/sites/globalchange/files/Citizen\%20Science\%20Workshop\%20Report\%20Final.pdf

[7] OSTP. 2014. National Plan for Civil Earth Observations. Washington, D.C., July 214. Accessed March $15,2021$. Available at:

https://obamawhitehouse.archives.gov/sites/default/files/microsites/ostp/NSTC/2014_national_plan_for_civil_earth_o bservations.pdf

[8] Crowdsourcing and Citizen science Act of 2016 (15 USC 3724). Accessed March 15, 2021. Available at: https://uscode.house.gov/view.xhtml?req=granuleid:USC-prelim-title15-section $3724 \&$ num=0\&edition=prelim and https://uscode.house.gov/statviewer.htm?volume=130\&page=3019

[9] White House OSTP. Champions for Change: Citizen Science. Accessed March 15, 2021. Available at: https://obamawhitehouse.archives.gov/champions/citizen-scientists

[10] The Open Government Partnership. 2013. Second Open Government National Action Plan of the United States of America. Published December 5, 2013. Accessed March 15, 2021. Available at https://obamawhitehouse.archives.gov/sites/default/files/docs/us_national action_plan_6p.pdf

[11] The Open Government Partnership. 2015. Third Open Government National Action Plan of the United States of America. Published October 27, 2015. Accessed March 15, 2021. Available at:

https://obamawhitehouse.archives.gov/sites/default/files/microsites/ostp/final_us_open_government_national_action plan_3_0.pdf

[12] Holdren, J.P. 2015. White House Memorandum: Addressing Societal and Scientific Challenges through Citizen Science and Crowdsourcing. Accessed March 15, 2021. Available at

https://obamawhitehouse.archives.gov/sites/default/files/microsites/ostp/holdren_citizen_science_memo_092915_0.pd $\underline{f}$

[13] Government Accountability Office. 2016. Open Innovation: Practices to Engage Citizens and Effectively Implement Federal Initiatives. October 13, 2016. Accessed March 15, 2021. Available at:

https://www.gao.gov/products/gao-17-14

[14] NASEM. 2018. Learning Through Citizen Science: Enhancing Opportunities by Design: A Consensus Study Report. Washington, D.C.: National Academies Press. doi: https://doi.org/10.17226/25183. Accessed March $15,2021$. Available at_https://www.nationalacademies.org/our-work/designing-citizen-science-to-support-science-learning

[15] OSTP. 2019. Implementation of Federal Prize and Citizen Science Authority: Fiscal Years 2017-18. Washington, D.C.: White House Office of Science and Technology Policy. Accessed March 15, 2021. Available at https://www.citizenscience.gov/2019/06/18/report-to-congress-2019/\# and_https://www.whitehouse.gov/wpcontent/uploads/2019/06/Federal-Prize-and-Citizen-Science-Implementation-FY17-18-Report-June-2019.pdf 
[16] NOAA. 2020. Draft Citizen Science Strategy: Federal Register Call for Public Comment, Deadline Sept 8, 2020. Accessed August 2020. Available at: https://www.federalregister.gov/documents/2020/08/06/2020-16895/publiccomment-for-a-draft-noaa-science-and-technology-strategy-citizen-science

[17] NOAA. 2021. NOAA's Citizen Science Strategy: Applying the Power of the Crowd. Washington, D.C.: National Oceanic \& Atmospheric Administration. Published and accessed January 15, 2021. Available at: https://nrc.noaa.gov/Portals/0/DraftCitizenScienceStrategy\%20(4).pdf?ver=2020-08-06-122218-450

[18] Shanley, L.A., Parker, A., Schade, S. and Bonn, A., 2019. Policy Perspectives on Citizen Science and Crowdsourcing. Citizen Science: Theory and Practice, 4(1), p.30. DOI: http://doi.org/10.5334/cstp.293

[19] Porticella, N., Bonfield, S., DeFalco, T., Fumarolo, A., Garibay, C., Jolly, E., Huerta Migus, L., Pandya, R., Purcell, K., Rowden, J., Stevenson, F., and Switzer, A. (2013). Promising Practices for Community Partnerships: A Call to Support More Inclusive Approaches to Public Participation in Scientific Research. A Report Commissioned by the Association of Science-Technology Centers, Washington, D.C

https://www.researchgate.net/publication/283153175_Promising practices_for_community_partnerships_A call to_s upport more inclusive approaches to Public Participation in Scientific Research

[20] Caruana, R., Lou, Y., Gehrke, J., Koch, P., Sturm, M., and Elhadad, N. 2015. "Intelligible Models for HealthCare: Predicting Pneumonia Risk and Hospital 30-Day Readmission." In Proceedings of the 21th ACM SIGKDD International Conference on Knowledge Discovery and Data Mining, 1721-1730. KDD '15. Sydney, NSW, Australia: Association for Computing Machinery. https://doi.org/10.1145/2783258.2788613.

[21] Vohland, K., and Gobel, C. 2017. Open Science and Citizen Science - a symbiotic relationship?. TATuP Zeitschrift für Technikfolgenabschätzung in Theorie und Praxis, v. 26, n. 1-2, p. 18-24, 15 Aug. 2017. Accessed on September 6, 2020 at: https://tatup.de/index.php/tatup/article/view/21

[22] Michelucci, P., "Human Computation and Convergence," in Handbook of Science and Technology Convergence, W. S. Bainbridge and M. C. Roco, Eds. Cham: Springer International Publishing, 2016, pp. $455-474$.

[23] SciStarter (n.d.). Verizon landing page. $\underline{\text { https://scistarter.org/Verizon }}$ 